\title{
Flexural Behaviour of Hardwood and Softwood Beams with Mechanically Connected GFRP plates
}

\author{
Marco CORRADI \\ Department of Engineering, University of Perugia, \\ Via Duranti, 9306125 Perugia, Italy \\ Email marco.corradi@unipg.it
}

Thuc P. VO

Department of Mechanical and Construction Engineering, Northumbria University, Newcastle upon Tyne, NE1 8ST, United Kingdom

\section{Keerthan POOLOGANATHAN}

Department of Mechanical and Construction Engineering, Northumbria University, Newcastle upon Tyne, NE1 8ST, United Kingdom

Adelaja Israel OSOFERO

School of Engineering, University of Aberdeen, Kings College, Aberdeen, AB24 3FX, United Kingdom 


\begin{abstract}
The use of Glass Fiber Reinforced Polymers (GFRP) can delay or prevent tension failure in timber beams and highly reduce tensile stresses in beams under loading. In this paper, the problem of reversibility, compatibility, and poor performance at high temperatures, of "traditional" organic adhesives was mitigated through the use of mechanical connections. The flexural behaviour of hardwood and softwood beams reinforced by mechanically connected composite plates, has been studied through series of experimental investigations and numerical modelling. The experimental program included strengthening and testing of a total of 91 beams (50 hardwood and 41 softwood). Each beam was loaded above its service load until complete failure. Different strengthening layouts and quantity of metal connectors were used. The increment in capacity and stiffness is the main focus of this paper and effects of strengthening on deflection, failure load and failure mode, strain, and hardwood beam ductility were discussed in details. The combination of different GFRP configurations with appropriate amount of metal connectors, led to the doubling of the maximum load carrying capacity of the beams.
\end{abstract}

KEYWORDS: GFRP Plates, Wood, Screwed Connection, Composite Materials, Bending Tests, Numerical Modelling.

\title{
1. INTRODUCTION
}

Timber structural components such as beams and ties have been extensively used in construction all over the world due to its low weight density and good mechanical properties. High tensile and flexural strengths are the main desirable timber characteristics in construction, 
especially when compared with historic masonry. Advantages of using timber have been documented in literature and its structural behaviour is particularly valued in seismic-prone areas, where lightweight and high tensile strength are critical [1-3]. Replacing old timber beams with concrete or steel beams is common place. However, this method cannot be used for the conservation of historic floors or other interesting architectural assets. Besides, it also increases the seismic vulnerability of structures due to high density and low deformation capacity of concrete. For this reason, conservation and retrofit is now considered an important task for structural engineers and architects when dealing with heritage structures. Even though tensile strength of timber is usually very high, defects and degradation during its life cycle highly impact on its mechanical properties. For example, knots and splits resulting from seasoning may cause up to $90 \%$ reduction of tensile strength in timber beams [1].

Previous research has focused on the application of composite materials bonded with organic adhesives to enhance timber beams' tensile capacity. Composites are usually introduced due to their characteristic high tensile strength and the ease of application. Composites commonly used include Fiber Reinforced Polymers (FRPs), Glass Fibre Glass (GFRP) and more recently, Carbon (CFRP), Aramidic (AFRP) and Basalt composites (BFRP). In reinforcing timber beams with composites, previous research have considered bonding of consolidated (pultruded) laminates [4-6], resin infusion of composite bar reinforcement into grooves [7-10] and wet lay up of FRP sheet reinforcement [11-14]. One of the first attempts of reinforcing timber using FRP sheets was by Plevris and Triantafillou in 1992 [15]. Trintafillou and Deskovic [16] also studied methods to pre-stress composites in order to anticipate composite reinforcement action. All these methods used epoxy or other organic adhesives for reinforcement application and this is their main limitation. These reinforcement methods have been extensively used in reinforcing structural timber components, for example bridge decks, trusses, timber floors, etc. [17-20]. Fig. 1 shows an on-site application of FRP strengthened timber beams. 
In application of composite materials for the reinforcement of timber structures, the following potential challenges should be noted 1) selection of appropriate composite material and applications method [21-23] and 2) the long-term behaviour of FRPs [24-28]. With regard to point 1), it can be noted that new composite materials are now available on the market with interesting sustainable characteristics (i.e. natural fibers). The long-term behavior of the reinforcement highly depends on the type of adhesives employed. Applications method involving the use of organic oil-based adhesives, e.g. epoxy resins, has become popular because of their remarkable mechanical properties which can guarantee adequate load transfer at interface between timber and composite. However, this compromised the reversibility of the intervention. The use of non-organic matrices and innovative connection mechanism have not been widely investigated and techniques involved are less established. In addition, extensive use of organic adhesives on listed timber structures is not encouraged by conservation authorities and ethical guidelines for conservation works on historic constructions often prescribe minimal intervention and the use of fully-reversible techniques [29]. Thus, efforts have been focused on the development of reversible application techniques of FRPs for the rehabilitation of timber structures with minimal compromise on the desired mechanical strength and behaviour.

The reinforcement method proposed in this work includes the use of GFRP pultruded plates attached to the beam's tension or lateral surfaces with metal screws. This is a fully reversible intervention procedure. This paper, which is an extension of research previously conducted by the authors on softwood beams and partially reported in [30], is focused on hardwood beams. The previous research involved only softwood beams whose structural behaviour is totally different, especially in axial tension for the high concentration of defects and its lower mechanical properties compared to hardwood. Results from soft and hardwood beams were also compared. 3D finite element models were carried out to take into account the non-isotropic 
behaviour of both wood and composite reinforcement. The problems related to the stress concentration in the area around the metallic connector were also considered to gain information and acquire knowledge of the failure mechanism and slippage phenomena between these two materials. Detailed numerical studies are currently underway to investigate the flexural behaviour of timber beams with mechanically connected GFRP plates.

\section{MATERIALS}

\subsection{Composite Plates}

Two types of composite plates made of GFRP (Types 1 and 2) were used for reinforcement of hard- and softwood beams. These plates underwent a mechanical characterization along fiber direction by performing tensile, compression and bending tests (Table 1). The mechanical properties of Type 1 and 2 are very similar with the tensile strengths of 376.4 and $368.6 \mathrm{MPa}$ and Young's moduli values of 33.3 and $31.57 \mathrm{GPa}$, respectively. According to the product catalogue database, these plates were made of E23 glass [31] and a thermoset polyester resin. The cost of the plate was about $5.5 £ / \mathrm{m}$ and the weight density of both types was about 1750 $\mathrm{kg} / \mathrm{m}^{3}$.

\subsection{Hardwood}

All beams were made of high-quality hardwood (English oak, Quercus Robur). A total of fifty beams were tested in bending: thirty beams had nominal dimensions of $65 \times 65 \times 1300 \mathrm{~mm}$ (small size) and the remaining twenty beams were $145 \times 145 \times 2450 \mathrm{~mm}$ (large size) (Fig. 2). Both series of beams had sharp corner edges and came from the same hardwood batch. All hardwood beams have been stored under controlled conditions at the Northumbria University's structures laboratory for a duration of 21 months before testing. The moisture content was $13.2 \%$ [35] with a Coefficient of Variation $(\mathrm{CoV})$ of $5.25 \%$ and weight density of $791.1 \mathrm{~kg} / \mathrm{m}^{3}$. 
All hardwood beams were tested in flexure up to failure. Twenty small and fifteen large beams were reinforced with the pultruded GFRP plates by using different plate configurations. Fifteen (10 small and 5 large) beams remained unreinforced as control specimens. Metal connectors were made of high-strength, grade 8.8 , coach screws and were applied in distinct geometrical arrangements (Fig. 3) [32].

Hardwood beams were classified as Strength Class D30 [33]. Mechanical properties of timber material were obtained from tests on small specimens and from results of un-reinforced beams (Table 2). A parallel to grain compressive strength of $31.7 \mathrm{MPa}$ was measured from $20 \times 20 \times 60$ mm hardwood specimens according to the specifications of ASTM D143 [34],

The tensile strength of the hardwood was obtained by performing 6 tensile tests using specimens without knots. Tensile strength value of $84.9 \mathrm{MPa}$ with a coefficient of variation $(\mathrm{CoV}) 18.1 \%$ was recorded. A linear stress-strain relationship is also recorded from tensile tests.

The results of bending tests on control beams were of particular interest as they provided important information about bending strength (Tables 3 and 4) which was $51.75 \mathrm{MPa}(\mathrm{CoV}$ $8.69 \%)$

\subsection{Softwood}

A detailed description of the mechanical properties of the softwood beams can be found in [30]. A total of 41 sharp-edged softwood beams (European silver fir, Abies Alba) were tested, 28 of which were reinforced with varying amounts of tensile reinforcement (GFRP plate, Type 2). Softwood beams were of Strength Class C18 [33]. Bending tests were conducted on beams with two different dimensions: 95x95x2000 mm (26 beams) and 200x200x4000 mm (15 beams). Results of mechanical characterization of softwood beams are also reported in Table 2 .

\section{EXPERIMENTAL PROCEDURES}




\subsection{GFRP Reinforcement Configurations}

GFRP composite plates, after being cut to the required dimensions, were applied on the beam's tensile or lateral sides with different configurations. The number and position of the steel connectors were also varied. Details of reinforcement configurations of softwood beams were reported in [30].

\subsection{Small hardwood beams}

The following configurations were investigated for small beams:

a. RET-type: two GFRP plates (8x40x1000 mm) applied laterally to the hardwood beam using $7 \mathrm{M} 8$ steel screws (screw length $=45 \mathrm{~mm}$ ) per plate. One screw was placed centrally on the plate while the remaining six were fixed at the plate's ends (three at each end) with a center-to-center distance of $70 \mathrm{~mm}$.

b. REN-type: two GFRP plates $(8 \times 80 \times 1000 \mathrm{~mm})$ applied laterally with identical number and type of screws (see previous configuration).

c. REM-type: one 8x80x1000 mm GFRP plate applied centrally on the beam tensile (bottom) side using a total quantity $12 \mathrm{M} 8$ steel screws (6 at each plate end).

\subsection{Large hardwood beams}

For large beams the following configurations have been used:

d. RES-type: one single $8 \times 80 \times 2000$ mm GFRP plate applied centrally on the beam's tensile side and connected using 8.8-grade, coach screws, at the beam's ends, where shearing force and distortions reach maximum values (Figs. 4-5).

e. REK-type: two overlapping 8x80x2000 mm epoxy-glued plates applied centrally on the beam's tensile side and connected using 8.8-grade, coach screws. 
f. RED-type: two adjacent 8x80x2000 mm plates, applied centrally on the beam's tensile side and connected using 8.8-grade, coach screws.

g. REL-type: two 8x80x2000 mm GFRP plates, applied on the lateral beam's surface using 8.8-grade, coach screws.

Four different screw arrangements were considered (Fig. 6):

No.1: Four screwed connections (two for each plate end) applied centrally on the GFRP plate using a spacing of $80 \mathrm{~mm}$ with a distance from plate's end of $50 \mathrm{~mm}$.

No.2: Six screwed connections (three for each plate end) applied centrally on the GFRP plate using a spacing of $80 \mathrm{~mm}$ with a distance from plate's end of $50 \mathrm{~mm}$ (Fig. 7).

No.3: Eight screwed connections (four for each plate end) applied in two rows, 4 at each end with $80 \mathrm{~mm}$ mutual spacing, positioned $20 \mathrm{~mm}$ from the plate lateral edges with $50 \mathrm{~mm}$ end distance.

No. 4: For lateral reinforcement, connectors were arranged along the plate with a centre-tocentre distance of $380 \mathrm{~mm}$ and $50 \mathrm{~mm}$ distance from the end.

Galvanized coach screws $16 \mathrm{~mm}$ diameter, grade 8.8, $130 \mathrm{~mm}$ length were employed to mechanically bond the GFRP plate to the beams' surface. Plates on each side were shifted by $95 \mathrm{~mm}$ from the timber centre line in opposite directions on opposite sides, leaving $190 \mathrm{~mm}$ distance between the holes in the timber. Some early results of the experimental campaign were at conference level and reported in [36].

\subsection{Test Set-up}

A four-point bending test on hardwood beams was carried out using as a reference UNI EN 408 standard [37]. Bending load was applied monotonically until failure was reached using an MTS $500 \mathrm{kN}$ capacity actuator at the Northumbria University's structures laboratory. Small hardwood beams had a square cross section with a $65 \mathrm{~mm}$ width, and a clear and load spans of 
1230 and $410 \mathrm{~mm}$, respectively. Initially, each beam was pre-loaded by applying a load of 0.2 $\mathrm{kN}$ and then tested with 2 concentrated loads applied at $1 / 3$ and $2 / 3$ of the clear span until complete failure.

For large hardwood beams, test and load spans were 2310 and $770 \mathrm{~mm}$, respectively. Span/depth ratios were 15.9 and 18.9 for small and large beams. Crosshead loading speed were controlled to ensure displacement rate of $4 \mathrm{~mm} / \mathrm{min}$ for all experiments. Deflections were recoded using a Linear Variable Differential Transducer (LVDT) incorporated into the actuator and measuring average beam's deflection at $1 / 3$ and $2 / 3$ of the test span. A spreader H-shaped steel beam was employed to divide the vertical bending load from the actuator into two vertical concentrated loads. End supports were made of 404.4 mm-diameter steel cylinders.

\section{TEST RESULTS AND ANALYSIS}

Four-point bending tests were used for measuring the load-capacity and stiffness modulus, as shown in Figs. 8 and 9. Several beams were tested without reinforcement in order to obtain data on the unreinforced timber beam bending strength. The bending strength was evaluated using the following elastic formulation, given by the UNI EN 408 standard [37]:

$$
f_{m}=\frac{M_{\max , n}}{I_{n}} \times \frac{h}{2}=a \frac{P_{\max }}{2 W}
$$

where $P_{\max }$ is the maximum bending load $(\mathrm{N}), M_{\max , n}$ is maximum bending moment between the load span about the neutral axis, $a$ is the distance between the point of the load and the nearest support, $I_{n}$ the second moment of the cross section about the neutral axis, $h$ is the beam's height and $W$ is the resistance modulus of the section.

Consequently, equation (2) was used to calculate the Young's modulus:

$$
E_{m, g}=\frac{l^{3}\left(P_{2}-P_{1}\right)}{b h^{3}\left(w_{2}-w_{1}\right)} \times\left[\left(\frac{3 a}{4 l}\right)-\left(\frac{a}{l}\right)^{3}\right]
$$


where $P_{2}-P_{1}$ is the change in bending load on the elastic portion of the load vs. deflection curve in $[\mathrm{N}] ; W_{2}-W_{1}$ is the change in deflection, corresponding to the $P_{2}-P_{1}$.

Beam specimens were given the notation AAA_1_1, where the three letters AAA denote the type of reinforcement applied (UNR= unreinforced, for reinforced RET, REN, REM, REK, RES, RED, REL as previously described). The first number is used to identify the hardwood beam (varying from 1 to 50), while the second denotes the type of screwed connection.

The results are discussed using the load versus vertical displacement response. For small beams, the average capacity of unreinforced beams was $15.25 \mathrm{kN}(\mathrm{CoV} 16.9 \%)$. The application of the GFRP plate reinforcement produced an increment in bending capacity varying from 27 to $88 \%$. RET- and REM-type configurations had an identical reinforcement ratio $\left(A_{r e \text { inf }} / A_{\text {timber }}\right)$ on the cross section of 0.151 , while this ratio was 0.303 for REN-type beams. However, REMtype configuration was more effective in terms of increment of capacity $(+59 \%)$, compared to RET-type (+27\%). By using an elastic theory and a modular ratio (assuming perfect bonding of GFRP to timber)

$$
m=\frac{E_{\text {GFRP }}}{E_{\text {timber }}}=3
$$

the second moment about the neutral axis was computed as $3.256 \times 10^{6} \mathrm{~mm}^{4}$ for REM-type configuration, while this was only $1.95 \times 10^{6} \mathrm{~mm}^{4}$ for RET-type. The latter configuration was used with the aim of reducing the stress concentration near the metal screws, preventing local failures in timber or screw's snaps. Comparable results were measured by analysing the capacity increments of beams reinforced with REN- (+88\%) and REM-type (+59\%) configurations: for these reinforcement layouts, the second moments differed only by $11.9 \%$. Beams reinforced according REM-type configurations collapsed due to timber tensile failure. With regard to the full-scale beams, five unreinforced beams (UNR-type) were tested in bending and an average bending capacity of $56.26 \mathrm{kN}$ was found. Bending strength of 42.63 MPa was calculated using eq. 1 (Fig 10). All beams were part of the same batch and the data 
collected during the experimental testing showed good repeatability between identical specimens. For unreinforced beams, $\mathrm{CoV}$ was only $12.7 \%$. Load-deflection plots for unreinforced and reinforced beams are shown in Figs. 10 and 11, while experimental bending strength values can be seen in Tables 3 and 4 .

The load-deflection relationship was essentially linear up to $70-80 \%$ of maximum bending load. For high bending loads, phenomena of wood yielding on the compression side led to reduction of the flexural stiffness with the consequence of flattering of the load-deflection curves. This was more evident for beams able to resist high bending loads as yielding in compression occurred for high compressive strength. Flexural stiffness was also calculated using the following formulation:

$$
k=\frac{P_{b}-P_{a}}{\delta_{P_{b}}-\delta_{P_{a}}}
$$

where $\delta_{F_{a}}$ and $\delta_{F_{b}}$ are the deflection values corresponding to $P_{a}$ and $P_{b}$ respectively and $\mathrm{k}$ is the slope of the secant line between $P_{a}=0.1 P_{\max }$ and $P_{b}=0.4 P_{\max }$.

For the RES-type reinforcement configuration (single GFRP plate placed on the beam's tension side), the reinforced beams were $41 \%$ stronger and $19.7 \%$ stiffer than the control ones. In addition, the reinforced beams were stiffer than the control beams, with an increment of the Young's modulus of up to $19.7 \%$. Fig. 8 shows the load applied by the hydraulic actuator, along with the test layout.

For the RED-type reinforcement configuration (2 overlapping GFRP plates), the reinforced beams showed an increase in bending strength of approximately $52 \%$ over the control. It is evident from the response of RED-type beams that the bending strength increases with increasing number of reinforcing GFRP plates. However, for a double-plate reinforcement, the bending strength increment exhibited a limited increment compared to the increment recorded for a single-plate reinforcement. This is because the failure is always initiated from the timber 
material and increase in the number of GFRP plates does not result in substantial increment of the beam capacity. All specimens of UNR-, RES- and RED-type failed in flexure (Figs. 9b and 12). For the reinforced specimens, failure was initiated in the timber material on the compression side with some limited yielding phenomena: by increasing the bending load, the neutral axis shifted downward and the tensile strains highly increased producing a positive stress transfer to the GFRP plate. However, tensile strains also increased in the timber material which was the main cause of beam failure.

By increasing the bending load, a decrease in flexural stiffness was observed: this was mainly caused by the previously discussed wood yielding phenomena in compression. Since screws were mainly applied at the ends of the beams where bending moment is negligible and the shearing force maximum, beams' failure was always experienced in the hardwood (Fig. 9b). This was never induced by the defects produced by drilling holes for screws installation.

Furthermore, it can be noted that $16 \mathrm{~mm}$-diameter steel screws never yielded nor locally deformed during the bending tests. Also, the absence of embedment in the area around the holes in the hardwood material demonstrated a satisfactory structural behaviour of the mechanical connection.

Table 5 compares the results of large softwood and hardwood beams. It can be clearly noted that the bending load-capacity of reinforced beams was significantly increased when hardwood beams were used. However, the increment measured from softwood beams was always smaller. The maximum load-capacity increment for hardwood beams was $76 \%$, while this was only $33 \%$ for softwood beams. Similar results can be observed by looking at the stiffness results (Young's modulus): for hardwood beams the maximum increment was $49.7 \%$ (REK-type), while this was only $21.3 \%$ for softwood beams (6 $18 \mathrm{~mm}$-diameter screws) (Table 5).

It is evident that the GFRP reinforcement is more effective when applied to hardwood beams. The reason for this can be found in the screwed connection and the high stress concentration in 
the area around the connectors when the reinforced beams were subjected to bending load. Timber is an orthotropic material and its parallel and transversal to grain compressive strengths are generally lower for softwood compared to hardwood. Following local failure in the area around the connector (Fig. 13), the embedment of the steel connector into softwood caused slippage phenomena between softwood and GFRP plate. This partially compromised the effectiveness of the GFRP reinforcement.

\section{PRELIMINARY NUMERICAL ANALYSIS}

Numerical models were developed using the finite element software ABAQUS [43] to simulate the flexural behaviour of timber beams reinforced by mechanically connected composite plates subjected to bending load. Individual constitutive models and failure criteria were described for the constituent materials.

\subsection{Modelling of GFRP composite using the modified 3D Hashin's failure criteria}

The composite GFRP plate was modelled using the modified Hashin's 3D failure criteria while the material properties were adopted from literature [37, 38]. The failure criteria in [39] were used to simulate the onset of damage and damage evolution of the composite in a cartesian coordinate system. The tensile-shear failure criteria, together with the related constitutive model, were implemented into a commercial available finite element tool - ABAQUS using a user-defined subroutine [40]. This was used to describe the damage initiation conditions in the warp and weft fibre directions, which is similar to the fibre failure criteria as follows:

$$
\begin{aligned}
& f_{1 t}=\left(\frac{\bar{\sigma}_{11}}{\sigma_{1 t}^{r}}\right)^{2}+\zeta\left(\frac{\bar{\sigma}_{12}}{\sigma_{12}^{r}}\right)^{2}+\left(\frac{\bar{\sigma}_{31}}{\sigma_{31}^{r}}\right)^{2}-1 \geq 0, \sigma_{11}>0 \\
& f_{2 t}=\left(\frac{\bar{\sigma}_{22}}{\sigma_{2 t}^{r}}\right)^{2}+\zeta\left(\frac{\bar{\sigma}_{12}}{\sigma_{12}^{r}}\right)^{2}+\left(\frac{\bar{\sigma}_{23}}{\sigma_{23}^{r}}\right)^{2}-1 \geq 0, \quad \sigma_{22}>0
\end{aligned}
$$


where the coefficient $\zeta=0.1$ controls the contribution of the shear component. Under shear loading, the material exhibits a plastic-like response, which becomes non-linear at low values of stress, while ultimate failure occurs at high values of strain. Since shear nonlinearity is not incorporated in the present model, to prevent premature predictions of failure, due to the contribution of shear component, its value was scaled down. The remaining three damage modes define damage under compression in the warp, weft and through-the-thickness direction. These are described by the maximum stress criteria as:

$$
f_{i c}=\left(\frac{\bar{\sigma}_{i i}}{\sigma_{i c}^{r}}\right)^{2}-1 \geq 0, \quad \sigma_{i i}<0, i=1,2,3
$$

The properties $\sigma_{1 t}^{r}, \sigma_{2 t}^{r}, \sigma_{1 c}^{r}, \sigma_{2 c}^{r}, \sigma_{3 c}^{r}, \sigma_{12}^{r}, \sigma_{23}^{r}, \sigma_{31}^{r}$ in Equations (5-7) are the damage initiation stresses.

\subsection{Material properties of constitutive model}

Material properties of the GFRP plates are listed in Table 1 and the properties of high-strength hardwood used in the modelling were obtained from experiment results of through shear and compression tests (Table 2). Orthotropic elastic material properties for hardwood are listed in Table 6.

\section{$5.33 D$ Timber beam modelling}

The timber beams were modelled as orthotropic elasto-viscoplastic materials using developed 3D finite element models, with viscoorthotropic linear elastic materials in tension and orthotropic elasto-viscoplastic materials in compression.

The linear orthotropic constitutive equation can be expressed as follows [41]:

$$
\{\varepsilon\}=\left[C^{e l}\right]\{\sigma\}
$$


where $\{\varepsilon\}$ is strain tensor, $\{\sigma\}$ is stress tensor and $\left[C^{e l}\right]$ is orthotropic elastic compliance matrix $(6 \times 6)$, i.e.

$$
\begin{gathered}
\{\varepsilon\}=\left\{\begin{array}{lllllll}
\varepsilon_{L} & \varepsilon_{R} & \varepsilon_{T} & \gamma_{L R} & \gamma_{L T} & \gamma_{R T}
\end{array}\right\}^{T} \\
\{\sigma\}=\left\{\begin{array}{lllllll}
\sigma_{L} & \sigma_{R} & \sigma_{T} & \tau_{L R} & \tau_{L T} & \tau_{R T}
\end{array}\right\}^{T} \\
{\left[C^{e l}\right]=\left[\begin{array}{ccccccc}
\frac{1}{E_{L}} & -\frac{v_{R L}}{E_{R}} & -\frac{v_{T L}}{E_{T}} & 0 & 0 & 0 \\
-\frac{v_{L R}}{E_{L}} & \frac{1}{E_{R}} & -\frac{v_{T R}}{E_{T}} & 0 & 0 & 0 \\
-\frac{v_{L T}}{E_{L}} & -\frac{v_{R T}}{E_{R}} & \frac{1}{E_{T}} & 0 & 0 & 0 \\
0 & 0 & & \frac{1}{G_{L R}} & 0 & 0 \\
0 & 0 & 0 & 0 & \frac{1}{G_{L T}} & 0 \\
0 & 0 & 0 & 0 & 0 & \frac{1}{G_{R T}}
\end{array}\right]}
\end{gathered}
$$

where $E_{L}, E_{R}, E_{T}$ are the Young's moduli in the longitudinal (L), radial (R) and tangential (T) principal directions of wood; $G_{L R}, G_{L T}, G_{R T}$ are the shear moduli in the $L-R, L-T, R-T$ planes; and $v_{i j}$ are the Poisson's ratios $(i, j=L, R, T)$.

\subsection{The Geometric Model}

The mesh generation, geometry, loading and boundary conditions for the beams reinforced by mechanically connected composite subjected to bending loading are shown in Fig. 14. The composite GFRP and timber beams were meshed using eight-noded solid elements with reduced integration (C3D8R elements). Mesh sensitivity was studied by varying the mesh density and through the thickness of the composite sheet. A number of interfaces were considered in the model, including that between the specimen and the supports and those between the composite timber beams and the GFRP plate. The GFRP plate interaction with the timber was modelled using the "surface to surface contact" option in ABAQUS. Fig. 14 shows 
the mesh generation of the beam, where finer meshes are created in the region around the hole for the GFRP plate and timber.

Detailed numerical studies are currently underway to investigate the flexural behaviour of hardwood and softwood beams with mechanically connected GFRP plates. Particular attention has been devoted to the analysis of the failure mode of the reinforced beams. In detail, for softwood beams, failure was initiated from the area around the connectors (embedment of the screws into timber). The proposed numerical model is able to capture these local phenomena with an error, in terms of bending load-capacity, of $23.7 \%$. Vice-versa, for hardwood beams, local failures are less important: hardwood beams typically failed due to the attainment of the wood (parallel to grain) compressive or tensile strength. Again, the numerical model was able to provide an acceptable estimation of the load-capacity of the beams with an acceptable error of $18.1 \%$.

\section{CONCLUSIONS}

The use of composite plates for reinforcement of pre-existing wood beams is proposed in the paper both as a provisional or definitive intervention to increase its bending capacity and stiffness. This reinforcement technique is economical and relatively easy to apply in relation to other strengthening methods employing epoxy adhesives or removal. 91 wood beams were reinforced using GFRP plates and tested in bending. GFRP material was mechanically connected using high-strength steel screws inserted into predrilled holes both on the timber and GFRP plate. This investigation is a continuation of a previous similar experimental campaign carried out on softwood beams and extended here to hardwood. Compared to the previous work, the effectiveness of the composite reinforcement is significantly higher and this can be attributed to the characteristics and behaviour of hardwood. In detail, the higher compressive strengths in all three principal directions of hardwood shows a more operational connection 
between hardwood and composite plate and this highly facilitated the stress transfer between the two structural materials.

Different reinforcement layouts were investigated. GFRP plates were fixed to the hardwood beams in one or two layers. The application of the composite plate produced up to $75 \%$ increase in bending capacity. Stiffness increases, compared to unreinforced hardwood beams, were also remarkable with increments of up to $49.7 \%$.

High-strength metal screws were applied at beam's ends where the bending moment was negligible and the shearing force maximum. Screws never yielded or locally deformed during bending tests. Also, the absence of embedment in the area around the holes in the wood material demonstrated a satisfactory structural behaviour of the mechanical connection. Beams' failure always occurred in the hardwood beam's tension side and it was never activated by the defects produced by drilling the holes.

The different configurations and number of connectors used for composite reinforcement seemed not to play a critical role in the stress transfer. Hardwood large beams reinforced using only 4 metal screws did not behave in a significantly different way compared to hardwood beams reinforced using 8 identical screws, highlighting the fact that the connection is not the weak element in the resisting mechanism.

GFRP plates never failed nor deformed both in the area around the holes or where bending moment was maximum. This again demonstrated that the structural behaviour of the reinforced beams is mainly governed by the timber tensile and compressive strengths and by the prevention of slippage phenomena at interface wood-GFRP plate. Most of the reinforced hardwood beams exhibited non-linear behaviour from the load-deflection curves, produced by timber yielding in compression. In order to avoid such failure modes, different solutions can be used: application of a composite reinforcement also on the compression side or use of stiffer composite plates. 
A nonlinear numerical model was developed to analyse the bending behaviour of GFRPreinforced hardwood beams. The model was moderately effective in predicting the mechanical performance of the beam. Detailed numerical studies are currently underway to investigate the flexural behaviour of hardwood and softwood beams with mechanically connected GFRP plates.

\section{ACKNOWLEDGEMENTS}

The authors thank Mr. Tomas Pupsys, Fahad Husain and Chun Chan. The authors are also grateful for support from the Structures Laboratory at Northumbria University in person of Leon Amess and Steve Colvin. The experimental activity was partially sponsored by research funds from UoA15 at Northumbria University.

\section{REFERENCES}

[1] Thelandersson S, Larsen HJ. Timber engineering, John Wiley \& Sons, 2003.

[2] Psycharis IN, Pantazopoulou SJ, Papadrakakis M. Seismic assessment, behavior and retrofit of heritage buildings and monuments. Springer, Vol. 37. Berlin, Germany, 2015.

[3] Ceccotti A. Structural behaviour of timber constructions in seismic zones, Workshop on Structural Behaviour of Timber Constructions in Seismic Zones (1989: Florence, Italy), 1990.

[4] Corradi M, Borri A. Fir and chestnut timber beams reinforced with GFRP pultruded elements. Compos Part B-Eng 2007;38:172-181.

[5] Raftery GM, Harte AM. Low-grade glued laminated timber reinforced with FRP plate. Compos Part B-Eng 2011;42:724-735.

[6] D’Ambrisi A, Focacci F, Raimondo L. Experimental investigation on flexural behavior of timber beams repaired with CFRP plates. Compos Struct 2014; 108: 720-728. 
[7] Gentile C, Svecova D, Rizkalla SR. Timber beams strengthened with GFRP bars: development and applications. J Compos Constr 2002;6:11-20.

[8] Micelli F, Scialpi V, La Tegola A. Flexural reinforcement of glulam timber beams and joints with carbon fiber-reinforced polymer rods. J Compos Constr 2005;9:337-347.

[9] Raftery GM, Whelan C. Low-grade glued laminated timber beams reinforced using improved arrangements of bonded-in GFRP rods. Constr Build Mater 2014;52:209-220.

[10] Righetti L, Corradi M, Borri A. Bond strength of composite CFRP reinforcing bars in timber. Materials 2015;8:4034-4049.

[11] Borri A, Corradi M, Grazini A. A method for flexural reinforcement of old wood beam with CFRP materials. Compos Part B-Eng 2005;36:143-153.

[12] De la Rosa García P, Cobo Escamilla A, González García MN. Bending reinforcement of timber beams with composite carbon fiber and basalt fiber materials. Compos Part B-Eng 2013;55:528-536.

[13] Kim YJ, Harries KA. Modeling of timber beams strengthened with various CFRP composites. Eng Struct 2010;32:3225-3234.

[14] Hay S, Thiessen K, Svecova D, Bakht B. Effectiveness of GFRP sheets for shear strengthening of timber. J Compos. Constr 2006;10:483-491.

[15] Plevris N, Triantafillou TC. FRP-reinforced wood as structural material. J Mater Civil Eng $1992 ; 4(3): 300-317$

[16] Triantafillou TC, Deskovic N. Prestressed FRP sheets as external reinforcement of wood members. J Struct Eng 1992;118(5):1270-84.

[17] Jasieńko J, Nowak TP, Bednarz Ł. Baroque structural ceiling over the Leopoldinum Auditorium in Wrocław University: tests, conservation, and a strengthening concept. Int $\mathbf{J}$ Archit Herit 2014;8:269-289. 
[18] Radford DW, Van Goethem D, Gutkowski RM, Peterson ML. Composite repair of timber structures. Constr Build Mater 2002;16:417-425.

[19] Schober KU, Harte AM, Kliger R, Jockwer R, Xu Q, Chen JF. FRP reinforcement of timber structures. Constr Build Mater 2015;97:106-118.

[20] Munafò P, Stazi F, Tassi C, Davì F. Experimentation on historic timber trusses to identify repair techniques compliant with the original structural-constructive conception. Constr Build Mater 2015;87:54-66.

[21] André A, Johnsson H, Carolin A. Natural fibre composites for strengthening of gluedlaminated timber in tension perpendicular to the grain. In3rd International conference on FRP composites in civil engineering (13-15 Dec. 2006) Miami, USA 2006 Dec.

[22] Borri A, Corradi M, Speranzini E. Reinforcement of wood with natural fibres. Compos Part B-Eng 2013;53:1-8.

[23] Raftery GM, Kelly F. Basalt FRP rods for reinforcement and repair of timber. Compos Part B-Eng 2015;1(70):9-19.

[24] Bank LC, Gentry TR, Barkatt A. Accelerated test methods to determine the long-term behavior of FRP composite structures: environmental effects. J Reinf Plast Compos 1995;14(6):559-87.

[25] Balázs GL, Borosnyói A. Long-term behavior of FRP. In: Composites in Construction: A Reality 2001 (pp. 84-91).

[26] Broughton JG, Hutchinson AR. Adhesive systems for structural connections in timber. International journal of adhesion and adhesives. 2001 Dec 31;21(3):177-86.

[27] Sen R. Developments in the durability of FRP-concrete bond. Construction and Building Materials. 2015 Mar 1;78:112-25.

[28] Vallée T, Tannert T, Fecht S. Adhesively bonded connections in the context of timber engineering-A Review. The Journal of Adhesion. 2017 Mar 21;93(4):257-87. 
[29] Ornelas C, Guedes JM, Breda-Vázquez I. Cultural built heritage and intervention criteria: A systematic analysis of building codes and legislation of Southern European countries. Journal of Cultural Heritage. 2016 Aug 31;20:725-32.

[30] Corradi M, Borri A, Castori G, Speranzini E. Fully reversible reinforcement of softwood beams with unbonded composite plates. Compos Struct 1492016 54-68.

[31] BS EN 13706-1:2002 Reinforced plastics composites. Specifications for pultruded profiles. Designation.

[32] EN 14399:2005 High-strength structural bolting assemblies for preloading.

[33] EN 338:2009. Structural timber - Strength classes.

[34] ASTM D143:2009. Standard test methods for small clear specimens of timber.

[35] EN 13183-1:2002. Moisture content of a piece of sawn timber. Determination by oven dry method.

[36]Pupsys T, Corradi M, Borri A, Amess L. Reversible tensile strengthening of full-scale timber beams with mechanically attached GFRP composite plates, MURICO 5 Mechanics of Masonry Structures Strengthened with Composite Materials, Bologna, Italy, 28-30 June 2017. [37] EN 408:2010. Timber structures. Structural timber and glued laminated timber: determination of some physical and mechanical properties.

[38] Vo TP, Guan ZW, Cantwell WJ, Schleyer GK. Modelling of the low-impulse blast behaviour of fibremetal laminates based on different aluminium alloys. Compos Part B $2013 ; 44: 141-51$.

[39] Zhou J, Hassan MZ, Guan, Z, Cantwell WJ The low velocity impact response of foambased sandwich panels. Compos Sci Technol 2012;72(14):1781-1790.

[40] Hashin Z. Failure criteria for unidirectional fibre composites. Appl Mech, 1980;47:32934. 
[41] Sitnikova E, Guan ZW, Schleyer GK, Cantwell WJ, Modelling of perforation failure in fibre metal laminates subjected to high impulsive blast loading. Int J Solids Struct 2014;51:3135-3146.

[42] Anshari B., Guan Z.W. and Wang Q.Y., Modelling of Glulam beams pre-stressed by compressed wood. Compos Struct 2017;165:160-170.

[43] ABAQUS Standard: User's Manual, Hibbitt, Karlsson \& Sorensen, Inc.; 2012. 
Table 1: Properties of GFRP plate.

\begin{tabular}{|c|c|c|}
\hline & Type 1 & Type 2 \\
\hline Fibrous Material & Glass Fiber, Type E & Glass Fiber, Type E \\
\hline Matrix & Thermoset Polyester Resin & Thermoset Polyester Resin \\
\hline Fillers & Mineral $\mathrm{CaCO}_{3}$ fillers & - \\
\hline Fabrication Process & Pultrusion & Pultrusion \\
\hline Thickness (mm) & 8.41 & 9.51 \\
\hline \multicolumn{3}{|l|}{ Tensile Properties } \\
\hline Sample Size & 6 & 6 \\
\hline Cross Section (mm) & $8.41 \times 15$ & $9.51 \times 15$ \\
\hline Tensile Strength (MPa) & $376.4 \quad(18.2)$ & $368.8 \quad(30.1)$ \\
\hline Young's Modulus (GPa) & $33.3(2.22)$ & $31.57(2.45)$ \\
\hline \multicolumn{3}{|l|}{ Compressive Properties } \\
\hline Sample Size & 6 & 6 \\
\hline Cross Section (mm) & $8.41 \times 50 \times 40$ & $9.51 \times 50 \times 40$ \\
\hline Compressive Strength (MPa) & $346.1 \quad(23.2)$ & $386.3 \quad(33.9)$ \\
\hline \multicolumn{3}{|l|}{ Bending Properties } \\
\hline Sample Size & 6 & 6 \\
\hline Cross Section (mm) & $8.41 \times 40 \times 100$ & $9.51 \times 40 \times 100$ \\
\hline Method & Three-Point Bending & Three-Point Bending \\
\hline Test Span (mm) & 80 & 80 \\
\hline Bending Strength $(\mathrm{MPa})$ & $351.8 \quad(13.6)$ & $373.8 \quad(36.2)$ \\
\hline
\end{tabular}

Standard Deviation SD in ( ) 
Table 2: Properties of hardwood and softwood.

\begin{tabular}{|c|c|c|c|}
\hline & Hardwood & \multicolumn{2}{|c|}{ Softwood } \\
\hline Scientific name & Quercus Robur & Abies & $l b a$ \\
\hline Strength Class & D30 & C18 & \\
\hline Weight density $\left(\mathrm{kg} / \mathrm{m}^{3}\right)$ & $791.1 \quad(31.1)$ & 423.9 & $(21.2)$ \\
\hline Moisture content (\%) & $13.2 \quad(0.69)$ & 12.8 & $(0.63)$ \\
\hline Tensile Strength (MPa) & $(15.4)$ & . & \\
\hline Young's Modulus (GPa) & - & 11.22 & $(1.68)$ \\
\hline Compressive Strength (MPa) & $(23.2)$ & 37.4 & $(3.34)$ \\
\hline Bending Strength (MPa) & $51.75 \quad(8.69)$ & 38.5 & $(9.21)$ \\
\hline
\end{tabular}

Standard Deviation (SD) in ( ) 
Table 3: Results of bending tests on small hardwood beams.

\begin{tabular}{|c|c|c|c|c|c|c|c|}
\hline Beam Index & $\begin{array}{l}\text { Max. Load } \\
{[\mathrm{kN}]}\end{array}$ & $\max$ & $\begin{array}{l}\text { Bending } \\
\text { Strength } \\
f_{m}[\mathrm{MPa}]\end{array}$ & $\begin{array}{l}\text { Deflectior } \\
\text { failure } w_{P} \\
{[\mathrm{~mm}]}\end{array}$ & & $\begin{array}{l}f_{m, \text { reinf }} / \\
f_{m, \text { unreinf }} \\
{[-]}\end{array}$ & \\
\hline UNR_1 & 17.26 & \multirow{10}{*}{$\begin{array}{l}15.25 \\
(2.59)\end{array}$} & 68.90 & 46.28 & \multirow{10}{*}{$\begin{array}{l}39.00 \\
(8.19)\end{array}$} & \multirow{10}{*}{-} & \multirow{10}{*}{ 型 } \\
\hline UNR_2 & 15.50 & & 61.80 & 36.55 & & & \\
\hline UNR_3 3 & 16.92 & & 67.50 & 31.32 & & & \\
\hline UNR_4 & 18.17 & & 72.50 & 44.55 & & & \\
\hline UNR_5 & 8.91 & & 35.50 & 45.23 & & & \\
\hline UNR_6 & 16.51 & & 65.90 & 47.08 & & & \\
\hline UNR 7 & 14.99 & & 59.80 & 34.10 & & & \\
\hline UNR_8 & 15.93 & & 63.6 & 46.89 & & & \\
\hline UNR_9 & 13.83 & & 55.30 & 23.34 & & & \\
\hline UNR_10 & 14.46 & & 58.50 & 34.65 & & & \\
\hline RET_11-2 & 19.10 & \multirow{8}{*}{$\begin{array}{l}19.37 \\
(2.75)\end{array}$} & 85.52 & 40.08 & \multirow{8}{*}{$\begin{array}{l}40.07 \\
(5.59)\end{array}$} & \multirow{8}{*}{1.27} & \\
\hline RET_12-1 & 18.80 & & 84.20 & 39.17 & & & \\
\hline RET_13-1 & 21.82 & & 97.71 & 44.17 & & & \\
\hline RET_14-1 & 18.05 & & 80.83 & 38.58 & & & \\
\hline $\mathrm{RET}_{-} 15-2$ & 17.57 & & 78.71 & 40.08 & & & \\
\hline RET_16-2 & 24.00 & & 107.5 & 49.84 & & & \\
\hline RET_17-2 & 20.53 & & 91.96 & 38.62 & & & \\
\hline RET_24-1 & 15.05 & & 67.41 & 30.01 & & & \\
\hline REN_18-5 & 24.43 & \multirow{6}{*}{$\begin{array}{l}28.59 \\
(4.05)\end{array}$} & 109.4 & 51.73 & \multirow{6}{*}{$\begin{array}{l}49.05 \\
(6.73)\end{array}$} & \multirow{6}{*}{1.88} & \\
\hline REN_19-4 & 26.34 & & 118.0 & 46.23 & & & \\
\hline REN_20-3 & 24.35 & & 109.1 & 37.33 & & & \\
\hline REN_21-5 & 32.62 & & 146.1 & 49.22 & & & \\
\hline REN_22-4 & 30.62 & & 137.2 & 53.17 & & & \\
\hline REN_23-3 & 33.20 & & 148.7 & 56.6 & & & \\
\hline REM_25 38 & 25.73 & \multirow{6}{*}{$\begin{array}{l}24.20 \\
(2.86)\end{array}$} & 101.2 & 33.31 & \multirow{6}{*}{$\begin{array}{l}48.06 \\
(12.76)\end{array}$} & \multirow{6}{*}{1.59} & \\
\hline REM_2637 & 26.44 & & 105.5 & 47.68 & & & \\
\hline REM_27 45 & 23.53 & & 98.23 & 47.37 & & & \\
\hline REM_28 23 & 21.42 & & 89.47 & 40.76 & & & \\
\hline REM_29 15 & 20.48 & & 88.32 & 47.88 & & & \\
\hline REM_30 20 & 27.61 & & 108.5 & 71.34 & & & \\
\hline
\end{tabular}

Standard Deviation in ( ). 
Table 4: Results of bending tests on large hardwood beams.

\begin{tabular}{|c|c|c|c|c|c|c|}
\hline Beam Index & $\begin{array}{l}\mathrm{Max} \\
{[\mathrm{kN}]}\end{array}$ & Load $P_{\max }$ & $\begin{array}{l}\text { Bending } \\
\text { Strength } \\
f_{m}[\mathrm{MPa}]\end{array}$ & \multicolumn{2}{|c|}{$\begin{array}{c}\text { Young's } \\
\text { Modulus [MPa] }\end{array}$} & $\begin{array}{l}f_{m, \text { reinf }} / \\
f_{m, \text { unreinf }} \\
{[-]}\end{array}$ \\
\hline UNR_31 & 67.23 & & 50.95 & 11217 & & \\
\hline UNR_32 & 47.42 & & 35.93 & 7596 & & \\
\hline UNR_33 & 46.88 & 56.26 & 35.52 & 9633 & 9731 & - \\
\hline UNR_34 & 64.37 & $(9.39)$ & 48.74 & 12653 & (2239) & \\
\hline UNR_35 & 55.42 & & 42.00 & 7555 & & \\
\hline RES_36_1 & 54.29 & & 41.14 & 8233 & & \\
\hline RES_37_1 & 85.70 & & 64.94 & 13441 & & \\
\hline RES_38_2 & 63.86 & 79.52 & 48.36 & 9723 & 11651 & \\
\hline RES_39_2 & 102.7 & $(24.5)$ & 76.55 & 13349 & (2791) & 1.41 \\
\hline RES_40_3 & 112.5 & & 85.18 & 15384 & & \\
\hline RES_41_3 & 58.10 & & 44.02 & 9775 & & \\
\hline RED_42_2 & 109.5 & & 82.90 & 16085 & & \\
\hline RED_43_2 & 82.62 & 87.18 & 61.43 & 13428 & 12930 & 1.52 \\
\hline RED_44_3 & 73.63 & $(15.47)$ & 55.76 & 10932 & (2376) & \\
\hline RED_45_3 & 83.01 & & 58.65 & 11274 & & \\
\hline REK_46_2 & 107.7 & 98.95 & 81.55 & 15620 & 14570 & 1.75 \\
\hline REK_47_2 & 90.23 & $(15.47)$ & 67.72 & 13519 & (1486) & \\
\hline REL_48_4 & 76.84 & & 58.18 & 11860 & & 1.51 \\
\hline REL_49_4 & 81.25 & 84.96 & 61.53 & 14080 & 13175 & \\
\hline REL 504 & 96.78 & $(10.47)$ & 73.31 & 13586 & (1166) & \\
\hline
\end{tabular}


Table 5: Summary of results of hardwood and softwood beams.

\begin{tabular}{|c|c|c|c|c|c|}
\hline $\begin{array}{l}\text { Wood } \\
\text { Species }\end{array}$ & Reinforcement & $\begin{array}{l}\text { No. of } \\
\text { GFRP } \\
\text { plates }\end{array}$ & $\begin{array}{l}\text { Bending } \\
\text { Strength } \\
f_{m}[\mathrm{MPa}]\end{array}$ & $\begin{array}{c}\text { Young's } \\
\text { Modulus [MPa] }\end{array}$ & $\begin{array}{l}f_{m, \text { reinf }} / \\
f_{m, \text { unreinf }} \\
{[-]}\end{array}$ \\
\hline Softwood & No & - & 38.54 & 8413 & - \\
\hline Hardwood & No & - & 42.63 & 9731 & - \\
\hline Softwood & $\begin{array}{l}8 \text { screws, } \\
8 \mathrm{~mm} \text { diameter }\end{array}$ & 2 & 38.89 & 8215 & 1.01 \\
\hline Softwood & $\begin{array}{l}12 \text { screws } \\
8 \mathrm{~mm} \text { diameter }\end{array}$ & 2 & 48.25 & 9125 & 1.25 \\
\hline Softwood & $\begin{array}{l}6 \text { screws } \\
18 \mathrm{~mm} \text { diameter }\end{array}$ & 2 & 48.12 & 9223 & 1.25 \\
\hline Softwood & $\begin{array}{l}6 \text { screws* } \\
18 \mathrm{~mm} \text { diameter }\end{array}$ & 2 & 49.72 & 9971 & 1.29 \\
\hline Softwood & $\begin{array}{l}6 \text { screws } * * \\
18 \mathrm{~mm} \text { diameter }\end{array}$ & 2 & 51.29 & 10211 & 1.33 \\
\hline Hardwood & $\begin{array}{l}\text { RES-type, } 16 \mathrm{~mm} \\
\text { diameter screws }\end{array}$ & 1 & 60.03 & 11651 & 1.41 \\
\hline Hardwood & $\begin{array}{l}\text { RED-type, } 16 \mathrm{~mm} \\
\text { diameter screws }\end{array}$ & 2 & 64.69 & 12930 & 1.52 \\
\hline Hardwood & $\begin{array}{l}\text { REK-type, } 16 \mathrm{~mm} \\
\text { diameter screws }\end{array}$ & 2 & 76.64 & 14570 & 1.75 \\
\hline Hardwood & $\begin{array}{l}\text { REL-type, } 16 \mathrm{~mm} \\
\text { diameter screws }\end{array}$ & 2 & 64.34 & 13175 & 1.51 \\
\hline
\end{tabular}

* with 2 steel brackets at the ends, ${ }^{* *}$ with 4 steel brackets at the ends [30] 
Table 6: Properties of hardwood from reference.

\begin{tabular}{cccc}
\hline & $\begin{array}{c}\text { Longitudinal } \\
(\mathrm{L})\end{array}$ & Radial (R) & Tangential (T) \\
\hline $\begin{array}{c}\text { Young's modulus E } \\
(\mathrm{MPa})\end{array}$ & 32858 & 3111 & 5945 \\
\hline & $\begin{array}{c}\text { Longitudinal- } \\
\text { Radial (LR) }\end{array}$ & $\begin{array}{c}\text { Longitudinal- } \\
\text { Tangential (RT) }\end{array}$ & $\begin{array}{c}\text { Radial-Tangential } \\
(\mathrm{RT})\end{array}$ \\
\hline Poisson Ratio (-) & 0.15 & 0.50 & 0.10 \\
Shear Modulus G (MPa) & 878 & 5717 & 1590 \\
\hline
\end{tabular}




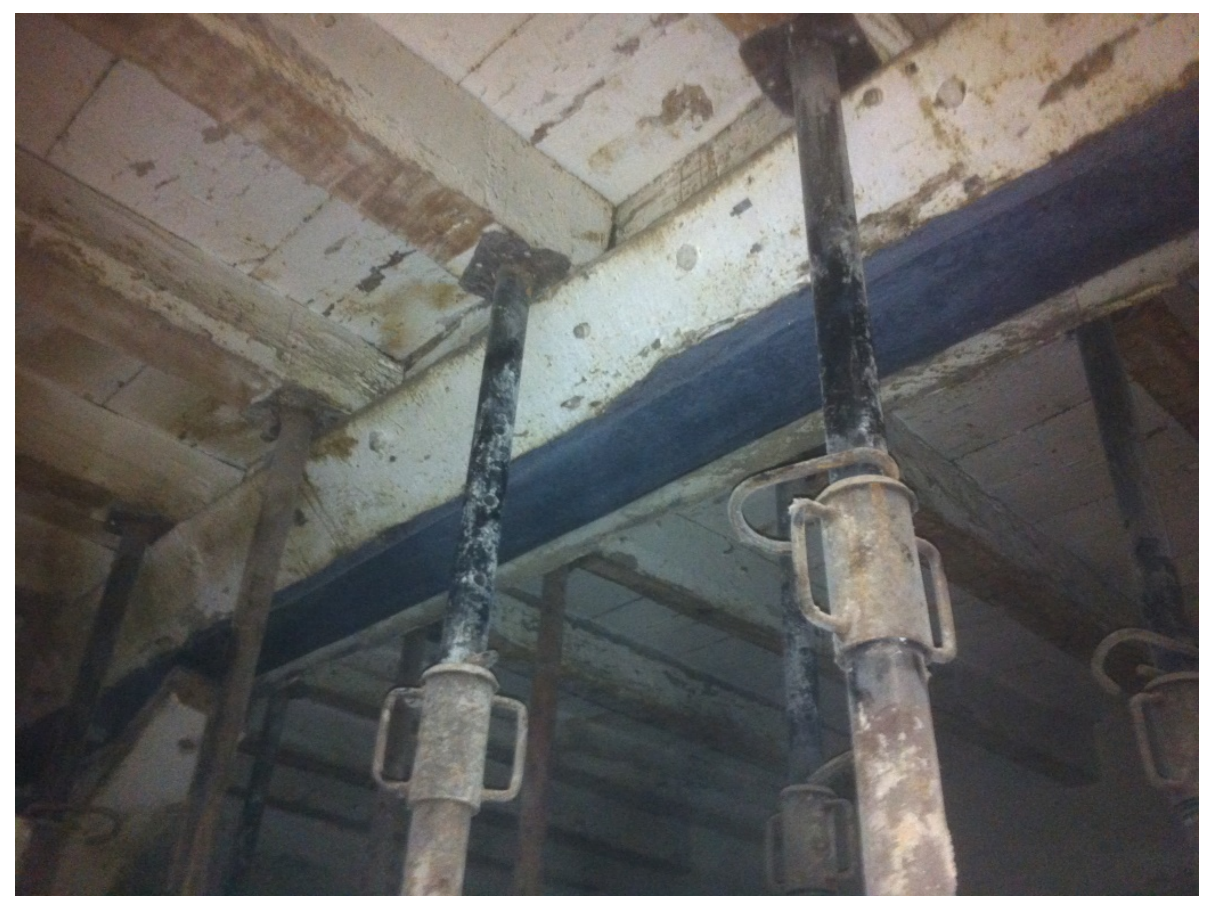

Figure 1: Applications of FRP strengthened timber beams. 

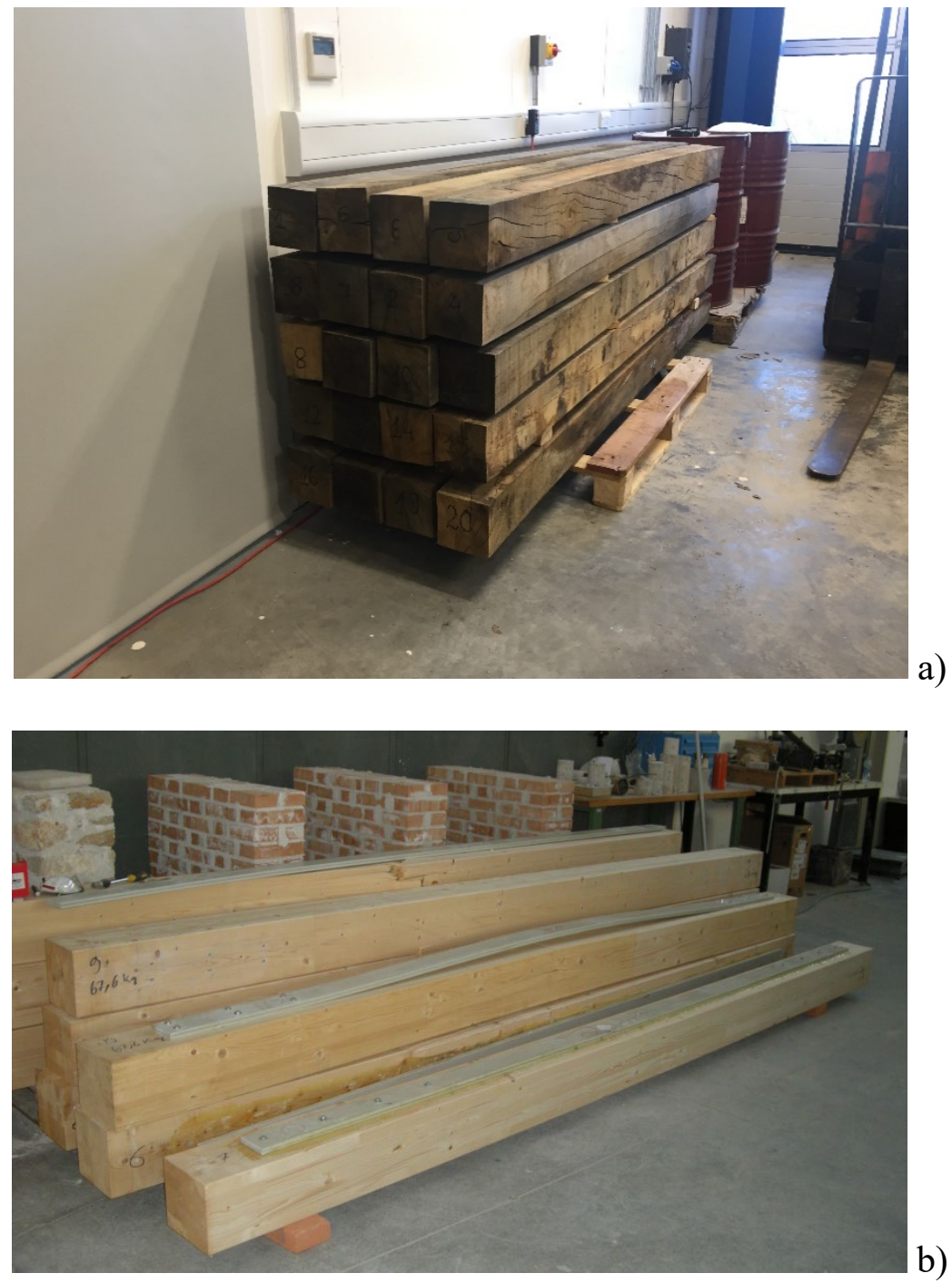

Figure 2: Hardwood a) and softwood b) beams before testing. 

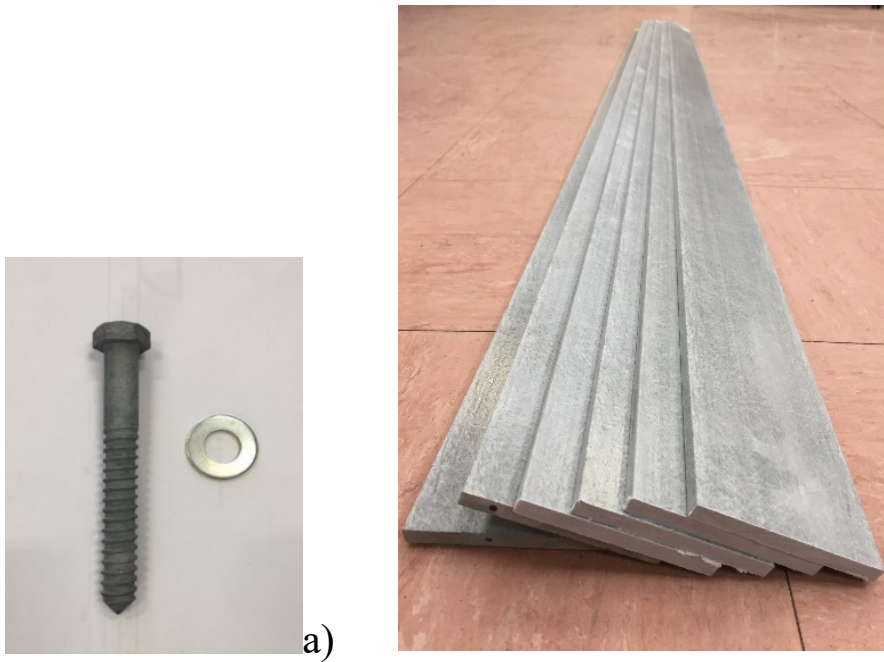

b)

Figure 3: a) 8.8 grade $16 \mathrm{~mm}$-diameter coach screws, b) 8.41 x $80 \mathrm{~mm}$ GFRP pultruded plate. 

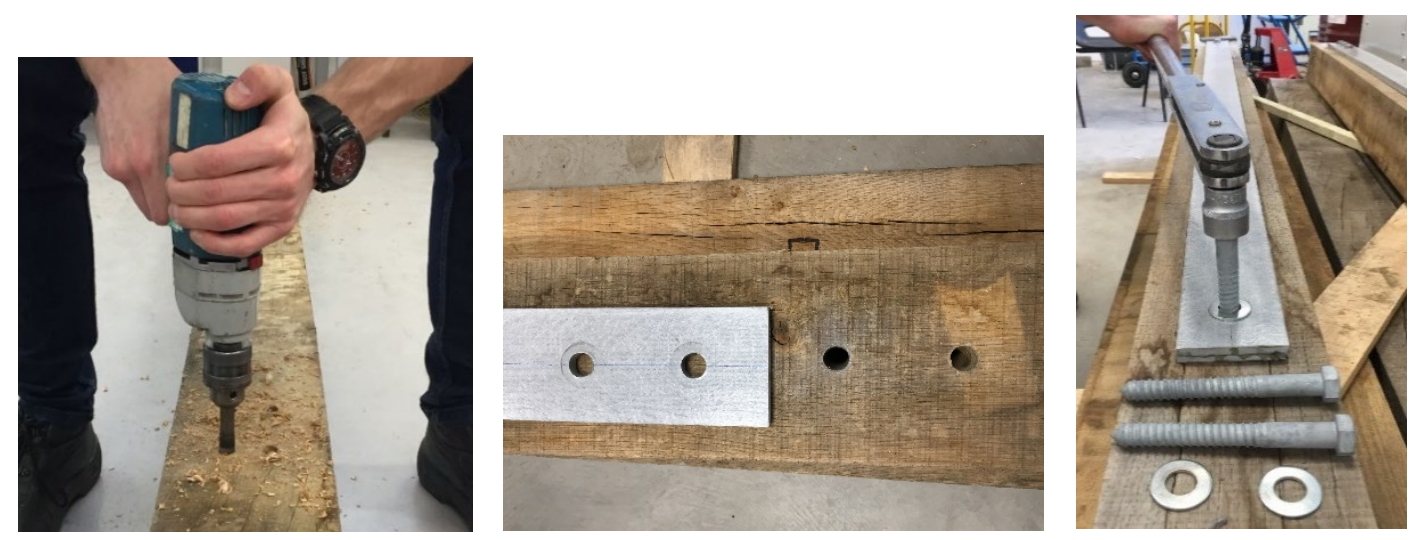

Figure 4: Installation method of the GFRP plates (hardwood beams). 


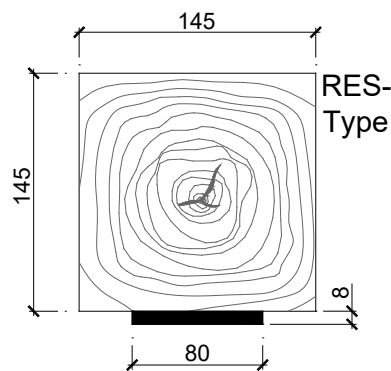

(a)

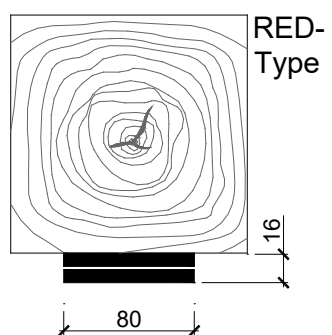

(b)

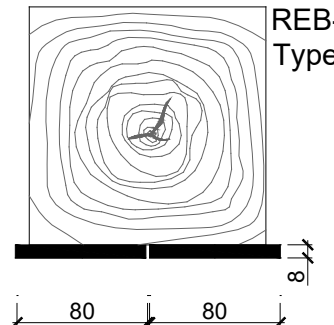

(c)

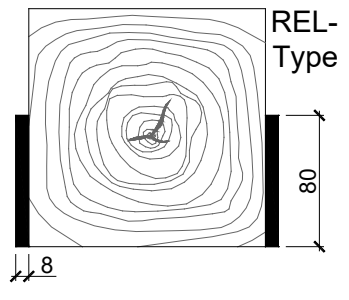

(d)

Figure 5: Reinforcement configurations of large hardwood beams:

(a) RES-type, (b) RED-type, (c) REK-type, (d) REL-type. 


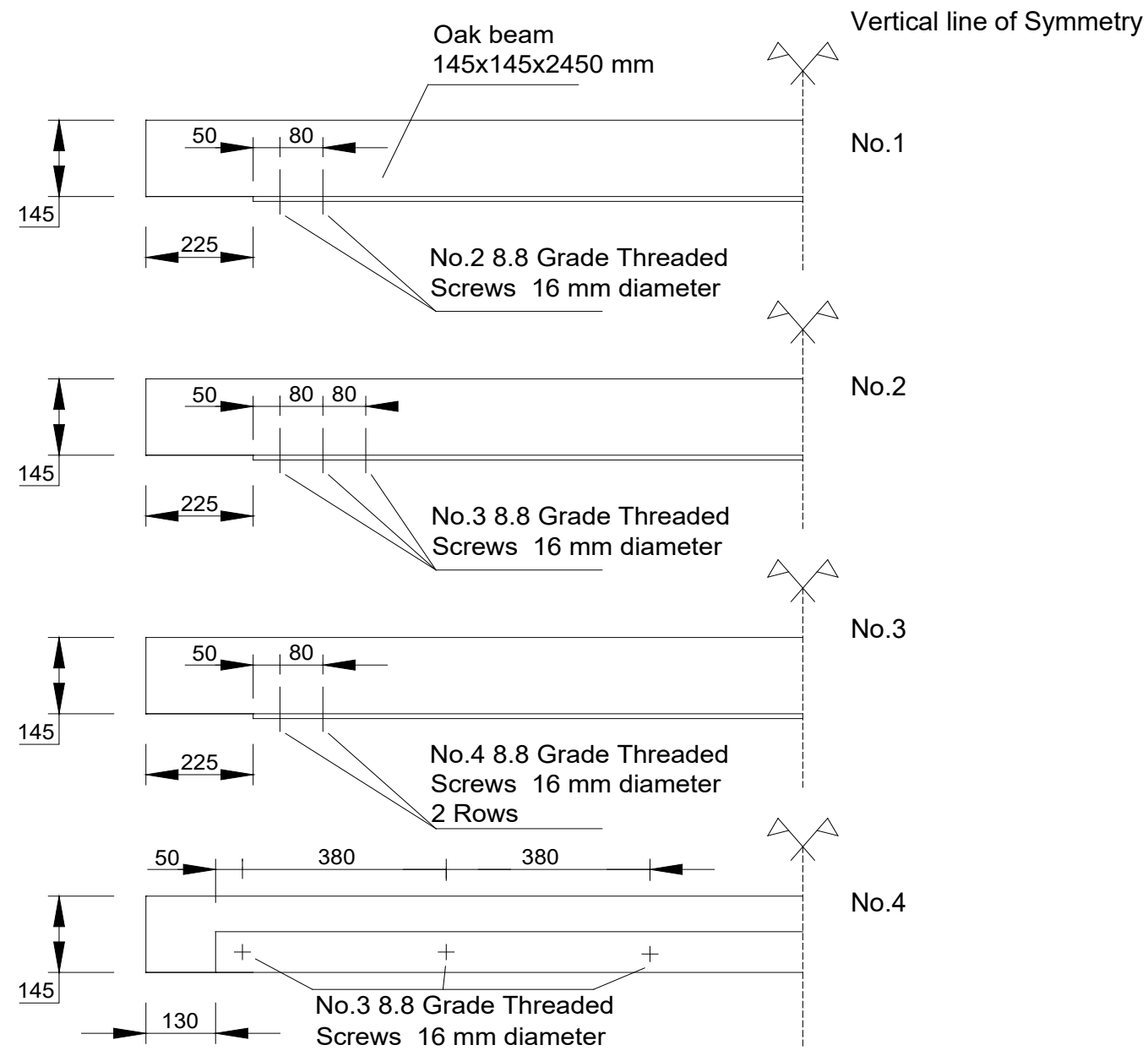

Figure 6: Screw arrangements (hardwood large beams): No.1: total 4 threaded screws, No.2 total of 6 threaded screws, No.3 total of 8 threaded screws, No. 4 total of 6 threaded screws 


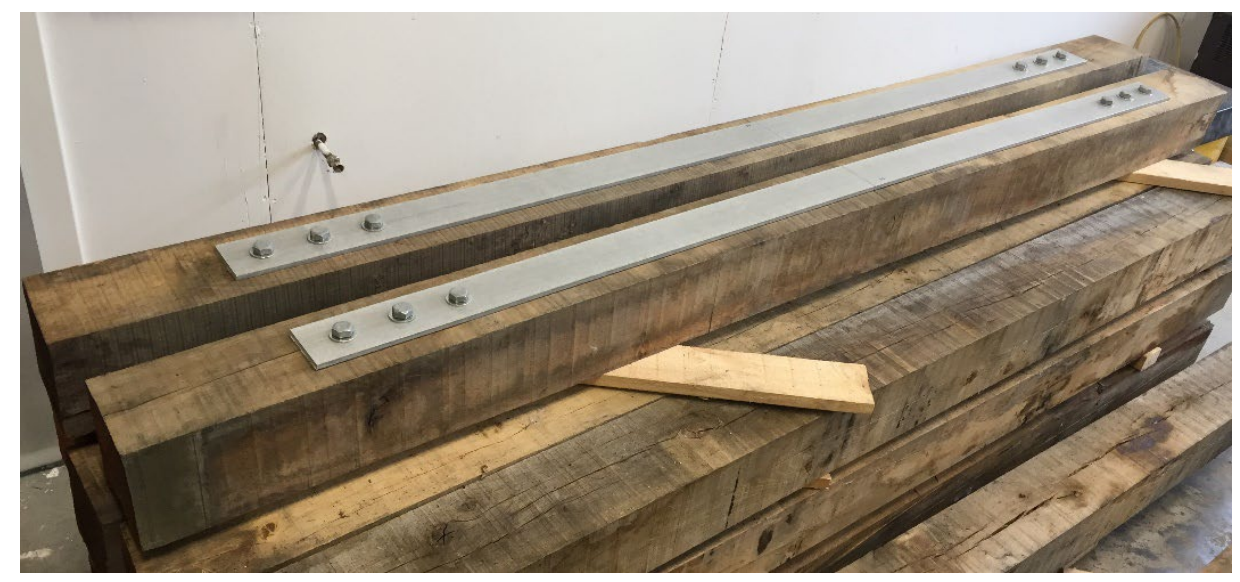

Figure 7: Hardwood beams reinforced according to screw configuration No. 2. 




Figure 8: Bending test of hardwood beams. 


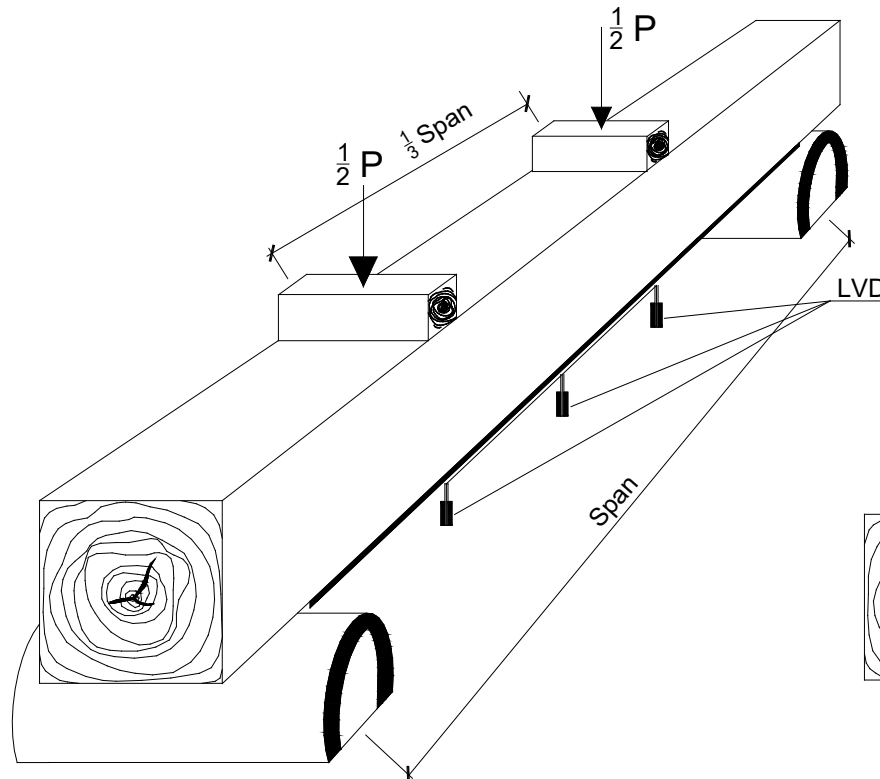

(a)

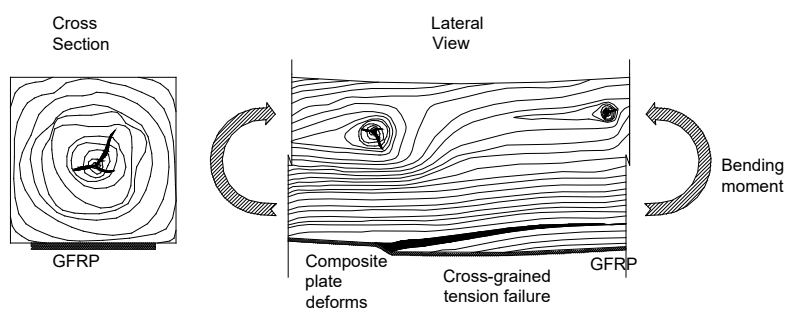

(b)

Figure 9 Test layout (a), typical bending failure (b) 


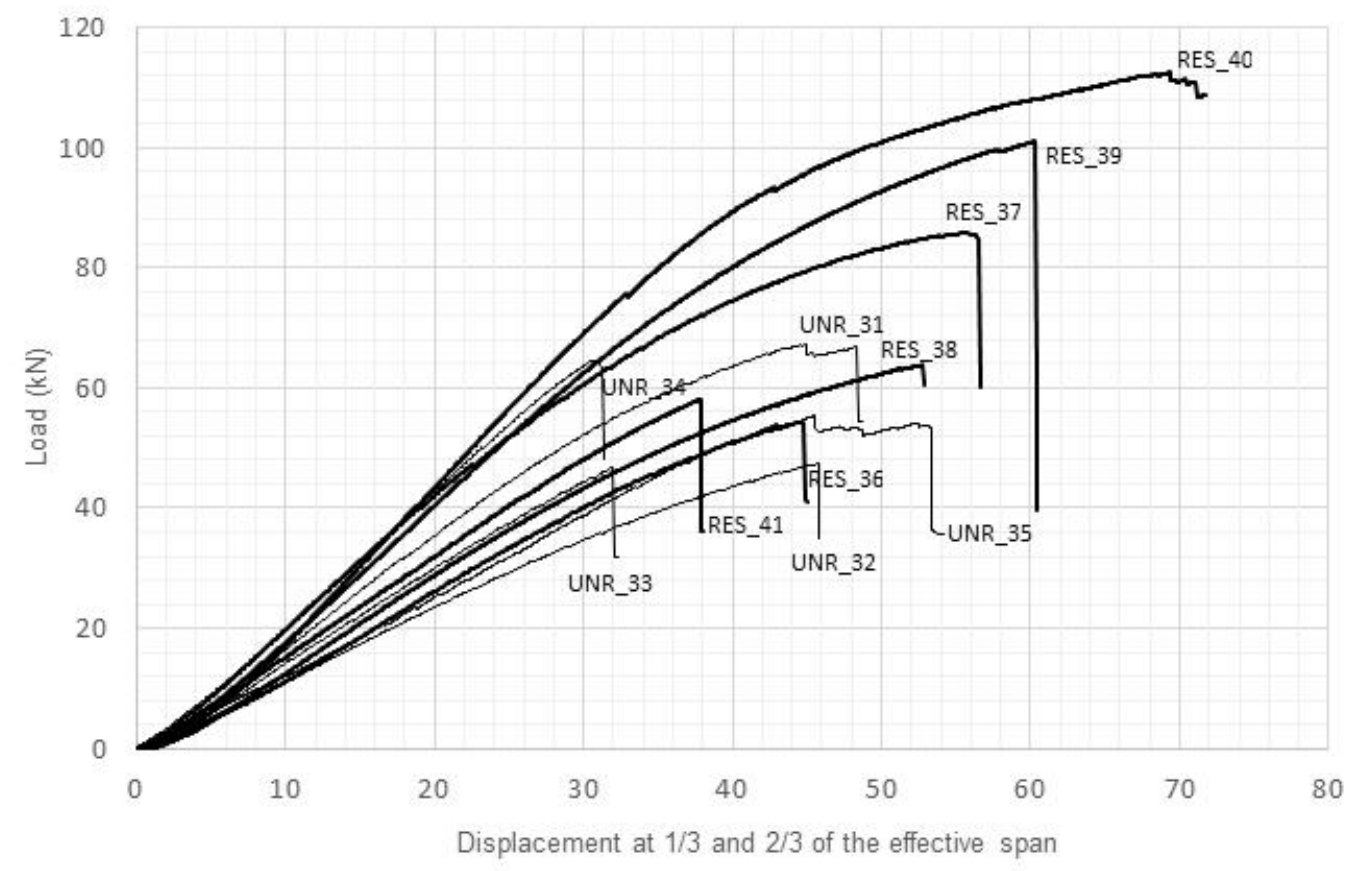

Figure 10: Compare the Load-deflection plot of hardwood with UNR (Unreinforced), and RES-type reinforcement. 


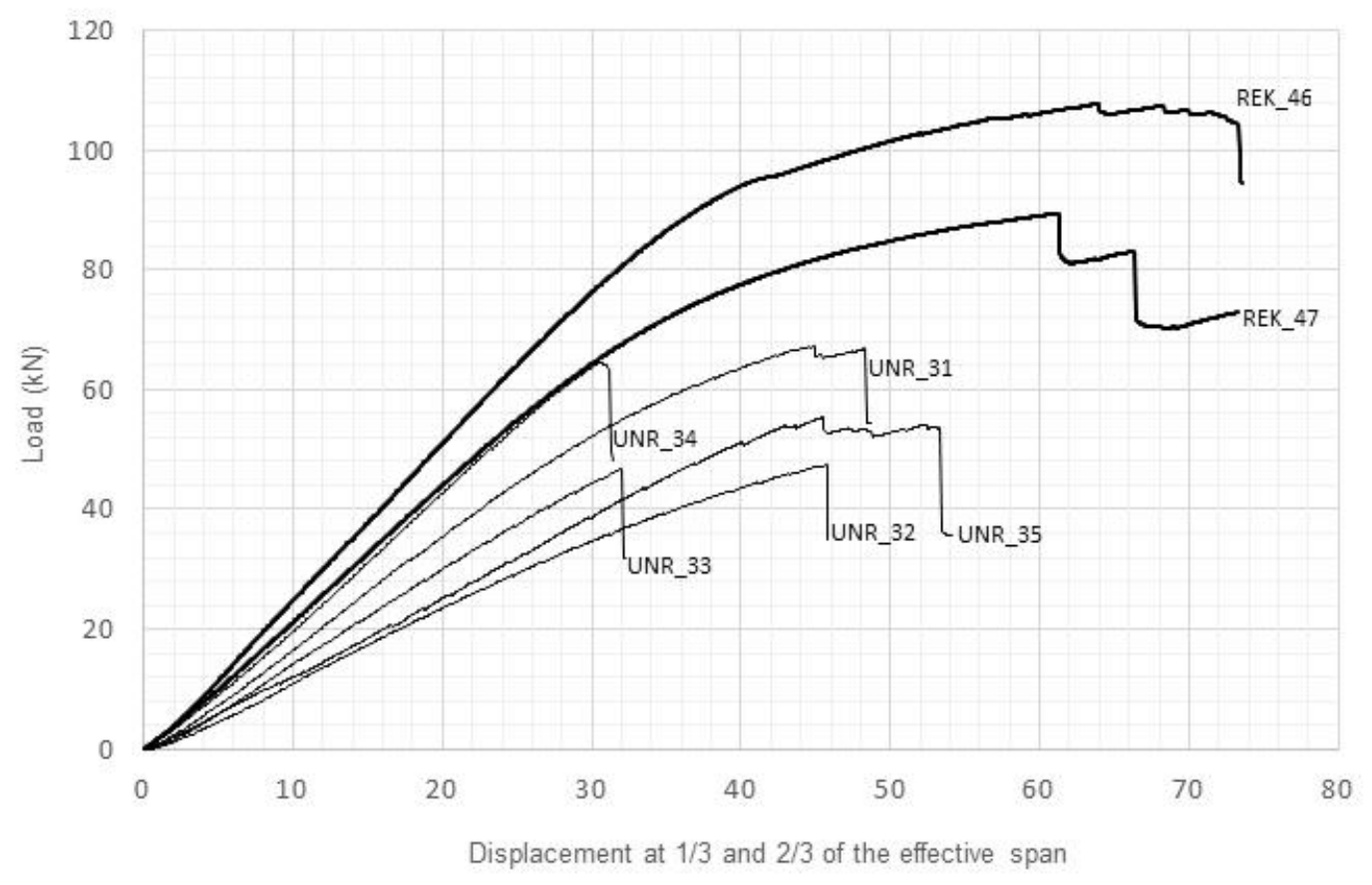

Figure 11: Compare the Load-deflection plot of hardwood with UNR (Unreinforced),, and REK-type reinforcement. 


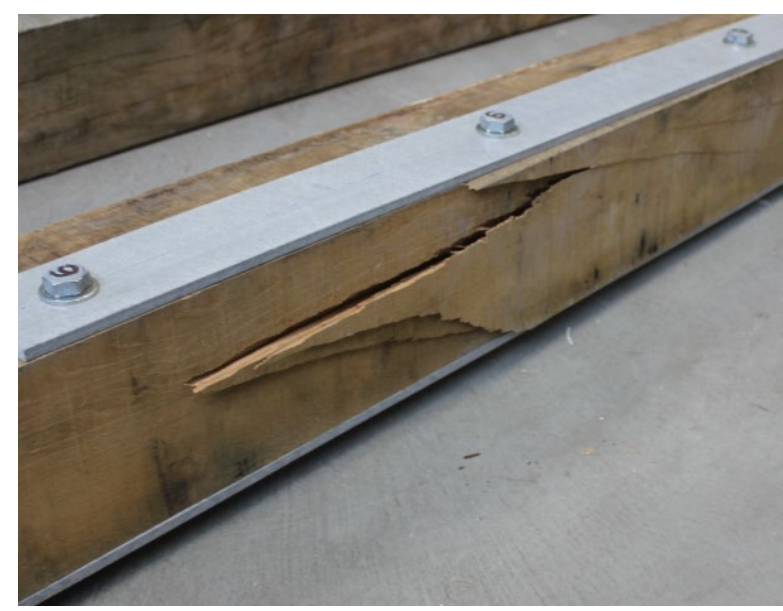

(a)

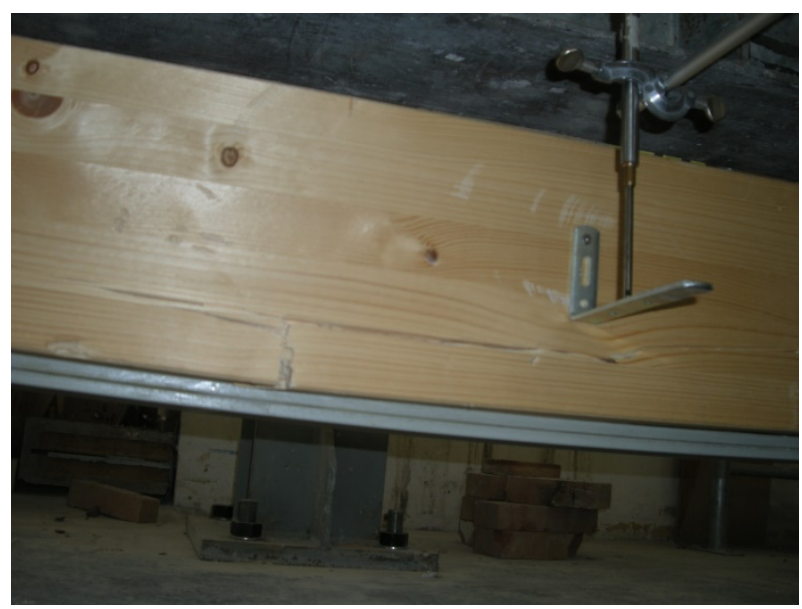

(b)

Figure 12: Failure Mode of beams with mechanically connected GFRP plates: a) hardwood,

b) softwood. 


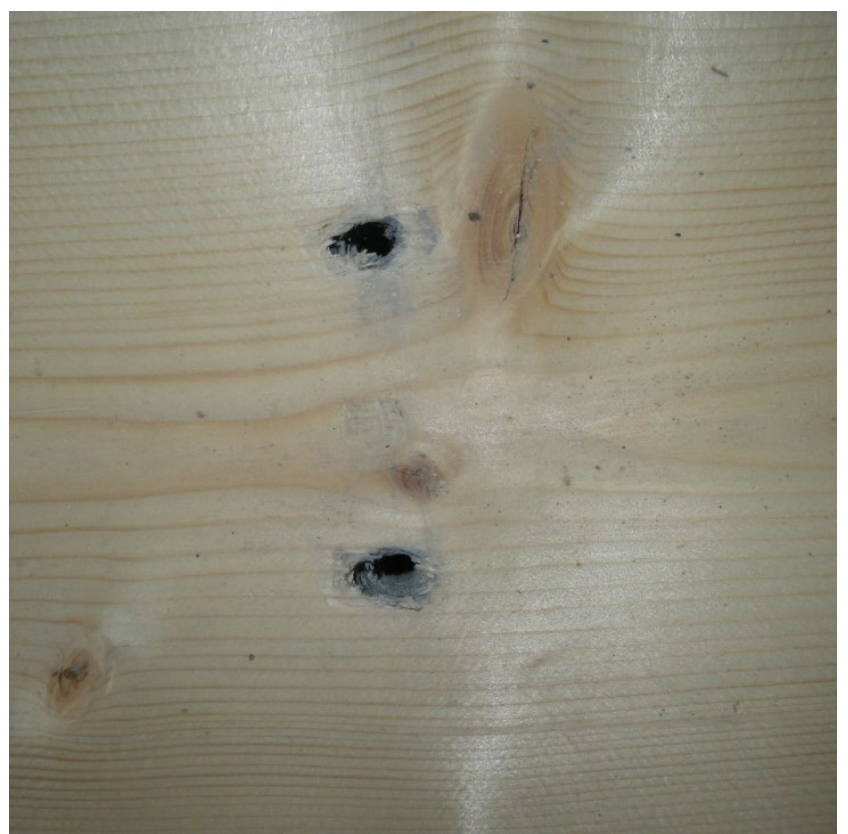

Figure 13: Typical local failure from embedment of the steel connector into softwood. 

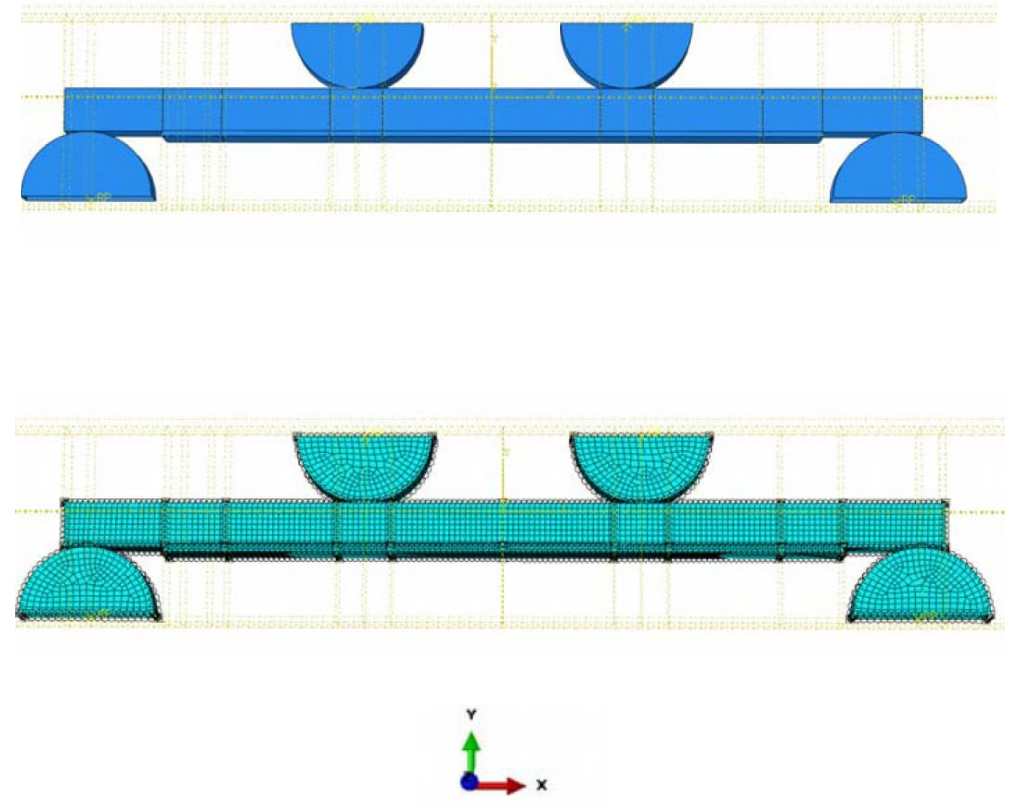

Figure 14: Finite element model of hardwood beams reinforced by GFRP composite plate model. 